\title{
Other Race
}

National Cancer Institute

\section{Source}

National Cancer Institute. Other Race. NCI Thesaurus. Code C104495.

Individuals who do not necessarily identify with any particular race or others who do not wish to self select into a racial category(ies). 